\title{
SOBRE O USO DA VARIÁVEL RAÇA-COR EM ESTUDOS QUANTITATIVOS ${ }^{1}$
}

\author{
Jerônimo Oliveira Muniz
}

\begin{abstract}
RESUMO
A crescente inclusão da raça no debate público brasileiro, o aumento da sua disponibilidade em pesquisas de opinião e monitoramento e a facilidade de inclusão da variável em modelos estatísticos tem provocado um paradoxo na importância da raça. Ao mesmo tempo em que a cor da pele vem ganhando relevância no debate politico, ela também vem perdendo a sua importância substantiva como um construto social complexo e dinâmico por ser utilizada de modo superficial, como uma categoria permanente e imutável em estudos quantitativos. Este ensaio bibliográfico discorre sobre os fatores que contribuem para essa tendência levando em conta a literatura nacional e internacional produzida nos últimos dez anos. Questiona-se o uso da raça em políticas públicas atentando-se para a sua confiabilidade, variabilidade e validade e discutemse as limitações e possibilidades de uso da raça como um demarcador de diferenças. $O$ ensaio conclui-se sugerindo uma agenda de pesquisa para aprimorar o entendimento e reduzir as incertezas associadas ao uso da variável "raça" em estudos quantitativos.
\end{abstract}

PALAVRAS-CHAVE: raça; cor da pele; Brasil; validade; confiabilidade; estabilidade; taxonomia; politicas públicas.

\section{INTRODUÇÃO}

O uso da variável "cor"2 em estudos quantitativos é cada vez maior. A incorporação de recortes raciais em debates e decisões políticas também. Nos Estados Unidos, esse aumento é constatado em estudos sociológicos (NIEMONEN, 1997), demográficos (ZUBERI, 2001, p. 94), e de saúde (JONES, LAVEIST \& LILLIE-BLANTOM, 1991; WILLIAMS, 1994; LAGUARDIA, 2004). Martin e Yeung (2003), por exemplo, investigaram a utilização da variável "raça" em Sociologia examinando a American Sociological Review, a revista de Ciências Sociais de maior prestígio nos Estados Unidos. Entre 1936 e 1999, eles constataram que o número de estudos empíricos levando em conta essa variável

1 O autor é grato a Natália Bueno, Fabrício Fialho, Stan Bailey, Mara Loveman e aos pareceristas anônimos da Revista de Sociologia e Política pelos comentários feitos ao artigo.

2 Por motivos de concisão, as expressões "raça" e "cor da pele" são utilizadas como intercambiáveis e sem aspas ao longo do texto. Apesar de reconhecer que existem diferenças etimológicas e etnológicas quanto à definição dos dois termos, eles devem ser entendidos como sinônimos nesta discussão. Dependendo da área da ciência (social ou bioló- aumentou de $8 \%$ para $40 \%$, enquanto o número de artigos que não mencionam raça ou cor da pele diminuiu de 70,7\% para 53,5\% (idem, p. 526).

No Brasil, observa-se tendência semelhante. No campo da Saúde Pública é cada vez maior o número de estudos ressaltando a relevância de diferenciais de acesso, morbidade e mortalidade devido à cor (ARAÚJO et alii, 2009), enquanto nos campos da Demografia, da Sociologia, da Economia e da Ciência Política continua-se a enfatizar os diferenciais de fecundidade, reprodução, mobilidade social, educação, renda e participação política (PAIXÃO \& CARVANO, 2008; THEODORO, 2008; RIBEIRO, 2009; BUENO \& FIALHO, 2009).

A crescente adoção de recortes raciais em estudos quantitativos tem gerado duas linhas

gica) sabe-se que a raça ou a cor pode ser entendida como o que ela realmente é: uma característica de indivíduos e de grupos, socialmente definida e relacionada à distribuição de poder em uma sociedade, podendo variar ao longo do tempo, do espaço e do contexto social; ou como o que ela não é: uma característica biológica e inata, que pode ser utilizada para explicar, identificar e classificar diferenças comportamentais, habilidades e oportunidades ao longo do ciclo de vida (SAPERSTEIN 2006, p. 57-58). 
interdependentes de argumentação crítica por aqueles que estudam e não simplesmente incorporam, a variável "raça" em suas análises. A primeira linha defende a importância de entenderse a variável "cor" como um conceito volátil e socialmente construído, com significados sociais importantes para a definição de identidades e experiências vividas. Esse argumento direcionase àqueles que consideram a cor da pele como uma característica permanente e imutável. O argumento é que, ao trivializarem a incorporação da cor em análises de correlação, os pesquisadores que utilizam essa variável reificam como fixo um conceito que é dinâmico, socialmente construído e fenotipicamente atribuível. Ao não questionarem ou esclarecerem a origem, as implicações, o significado e a mensuração da raça, os usuários da variável estariam contribuindo para a sua banalização. Em uma segunda linha de argumentação, e como um corolário do fato de a raça ser um construto social, tem-se questionado o uso da variável na tomada de decisões políticas, atentando-se para a sua confiabilidade, variabilidade e validade. Afinal, sendo a cor uma característica social putativa contextual, é legítimo perguntar em que extensão ela pode ou deve ser utilizada como um demarcador confiável para a atribuição de benefícios e para a identificação de diferenças.

O propósito deste ensaio bibliográfico é apresentar e discutir essas duas linhas de argumentação à luz da literatura nacional e internacional produzida nos últimos dez anos, tendo em vista a crescente adoção da variável "cor" em estudos quantitativos e em debates políticos. A primeira parte do ensaio discorre sobre as razões que têm conduzido ao uso indiscriminado da variável "raça" em estudos quantitativos. A segunda parte debate o uso da variável em políticas públicas e faz um contraponto sobre a sua utilização como um mecanismo sinalizador de desigualdades e de alocação de privilégios. A terceira parte aponta as possibilidades e limitações dessa variável em estudos quantitativos, sugerindo algumas possibilidades de análise que vêm ganhando força nos Estados Unidos, mas que ainda têm sido pouco exploradas no Brasil. A parte final do ensaio conclui a crítica sobre o uso da raça em estudos quantitativos e mostra que o embate entre estudiosos da raça - aqueles que investigam a dinâmica e a formação das fronteiras raciais - e analistas raciais - aqueles que simplesmente empregam a variável em suas análises - é mais uma questão de abordagem, prioridade e foco da variável de interesse do que de incompatibilidade metodológica e negligência científica.

\section{SOBRE O USO DA VARIÁVEL RAÇA (OU COR) EM ESTUDOS QUANTITATIVOS}

Desde Casa-grande e senzala (FREIRE, 1933), vários autores dedicaram-se a pensar as relações e a formação raciais do Brasil (Oracy Nogueira, Antonio Sérgio Guimarães, Edward Telles, Donald Pierson, Carl Degler, Carlos Hasenbalg etc.). Entretanto, ainda são raros os estudos que analisam a dinâmica das fronteiras raciais, a constituição de identidades raciais, os motivos que levam alguém a classificar-se em uma ou em outra cor e as razões que fazem que alguém mude de uma para outra graduação de tom de pele ao longo da vida. Ao invés de questionarem a construção e a dinâmica das categorias raciais, o que se tem observado é uma crescente incorporação da variável "raça" em estudos que a assumem como dada e "invariável", fixa, permanente. A substância da raça, os fatores e contextos espaciais, temporais e culturais que afetam e tornam a cor da pele uma característica socialmente construída têm sido pouco investigados. Há exceções a essa tendência (ex. BAILEY, 2009; LOVEMAN \& MUNIZ, 2007; SCHWARTZMAN, 2007), mas se examinarmos a massa de estudos feitos por demógrafos, economistas, cientistas políticos, profissionais de saúde e mesmo por sociólogos, a conclusão de que a raça tem perdido importância como uma categoria a ser analisada, e não de análise, tornase inevitável. Há assim um paradoxo de relevância. Ao mesmo tempo em que a raça ganha importância no debate político ao ser muito e superficialmente utilizada em estudos quantitativos, ela também perde importância ao ser utilizada sem profundidade. Uma série de razões complementares tem contribuído para essa vulgarização da raça em estudos quantitativos.

A primeira dessas razões está relacionada à maior disponibilidade da variável em pesquisas de opinião e monitoramento estatístico. Apesar de ao longo do tempo terem ocorrido mudanças nas opções de classificação, a informação sobre cor da pele vem sendo coletada pelos censos demográficos desde 1872 . Nesse ano a população foi classificada entre livre e escrava, cabendo ao recenseado livre definir a sua cor e a de seus escravos. Depois disso, a investigação sobre cor 
esteve presente nos censos de 1890, 1940, 1950, 1960, 1980 e nos Suplementos de Mobilidade e Cor de 1976, de Educação de 1982, de Fecundidade de 1984, do Menor de 1985 e no Suplemento de 1986. A Pesquisa Nacional de Amostra de Domicílio (PNAD) também tem coletado anualmente a informação sobre cor da pele desde 1987, quando incluiu pela primeira vez no seu corpo básico a investigação sobre a cor (ARAÚJO, 1987). A partir de 1996, a inclusão da informação sobre raça e cor no Sistema de Informações de Nascidos Vivos (Sinasc) tornouse obrigatória. A Pesquisa Mensal de Emprego do Instituto Brasileiro de Geografia e Estatística (IBGE), conduzida em grandes regiões metropolitanas do país, também coleta a raça ou cor desde dezembro de 2002 utilizando as mesmas categorias do censo: branca, amarela, indígena, preta e parda. $\mathrm{O}$ mesmo tem sido feito pelo Censo Escolar desde 2005.

A informação sobre raça também tem sido coletada e analisada em pesquisas recentes e de periodicidade irregular, mas que têm possibilitado uma gama de perguntas relacionadas à raça que vão além do simples monitoramento da composição racial brasileira. Entre essas destacam-se as pesquisas do Instituto DataFolha, realizadas em 1995 e em 2008; a Pesquisa Social Brasileira, realizada em 2002 e 2004 pelo Núcleo de Pesquisas, Informações e Políticas Públicas da Universidade Federal Fluminense (DataUFF), e a Pesquisa da Região Metropolitana de Belo Horizonte, conduzida em 2002, 2005 e 2008 pela Universidade Federal de Minas Gerais (UFMG). Essas pesquisas recentes, em particular, têm servido de insumo para artigos científicos que mensuram a consistência entre metodologias distintas de coleta da informação sobre cor e avaliam as implicações empíricas e sociais resultantes de uma ou de outra forma de classificação racial (TELLES \& LIM, 1998; BAILEY \& TELLES, 2006; SIMÕES \& JERONYMO, 2007; BAILEY, 2008). Ao analisarem a cor da pele de um ponto de vista substantivo, indo além da simples dicotomização e "controle" da variável "raça", esses estudos valorizam as implicações sociais que a raça pode ter em termos de percepções de desigualdade de renda, escolaridade, localização geográfica, segmentação ocupacional e outras características relevantes. Graças à diversificação das formas de coleta da informação racial contida nessas pesquisas, o foco da abordagem racial empírica vem avançando de mecanicista para substantivo, valorizando assim o aspecto construtivista da "raça" e as suas implicações sociais e estatísticas. Ao focalizarem os motivos que levam à inclusão em determinada categoria racial e nos componentes socioeconômicos, culturais e contextuais que conduzem ao deslocamento das fronteiras raciais, esses autores valorizam a substância da raça.

As crescentes inserção e diversificação das formas de coleta do quesito cor em surveys e pesquisas oficiais de levantamento estatístico têm corroborado o aumento de estudos substantivos, que não só "levam em conta" a raça, mas que também se preocupam em entender os significados e os fatores envolvidos na construção e na dinâmica das fronteiras raciais. Os estudos substantivos valorizando a raça como objeto de análise, e não como algo a ser superficialmente levado em conta, entretanto, ainda são minoria.

A segunda razão contribuindo para o aumento do uso da raça em estudos quantitativos relacionase ao debate político vigente. A importância da raça e a sua crescente inclusão em pesquisas é diretamente proporcional ao status atribuído a ela por políticos, pelos meios de comunicação e pelo debate popular e acadêmico. A importância da raça no debate político é evidente se mencionarmos as várias mudanças legais ocorridas desde o final dos anos 1980, entre as quais se destaca o estabelecimento de disposições antidiscriminatórias na Constituição Federal de 1988, que transformou o racismo em crime inafiançável, protegeu a manifestação das culturas indígenas e afrobrasileiras, determinou a proteção legal aos documentos e locais dos antigos quilombos e garantiu o reconhecimento das terras ocupadas pelos quilombolas remanescentes. Outra conquista são os projetos de Lei de Cotas (Projeto de Lei n. 73/1999) e do Estatuto da Igualdade Racial (Projeto de Lei n. 3 198/2000), já aprovados na Câmara dos Deputados e atualmente em votação no Senado Federal.

No final de 2001, várias ações afirmativas foram implementadas para combater a discriminação e aumentar a participação de negros em órgãos públicos, ministérios e universidades ${ }^{3}$.

\footnotetext{
3 Na maioria dos decretos ministeriais o termo "negro" foi utilizado. A inclusão de pardos dentro do termo "negro"
} 
Mais especificamente, decretos foram baixados para garantir que pelo menos $20 \%$ de todas as posições administrativas no Ministério da Agricultura e 30\% do orçamento ministerial fosse alocado para comunidades majoritariamente negras. Em 9 de novembro de 2001, a Assembléia Legislativa do Rio de Janeiro anunciou que 40\% das admissões na Universidade Estadual do Rio de Janeiro (UERJ) e na Universidade Estadual do Norte Fluminense Darcy Ribeiro (UENF) seriam reservadas para pretos e pardos. Um pouco antes, a UERJ reservara $50 \%$ das vagas para estudantes provenientes de escolas públicas. Em dezembro do mesmo ano, o Ministério da Justiça e o Supremo Tribunal Federal ordenaram que pelo menos 20\% dos consultores, funcionários e empregados fossem negros. Ações afirmativas também foram aprovadas para prover 20 bolsas anuais para estudantes negros no Instituto Rio Branco. Em 24 de março de 2002, o Ministério do Trabalho decretou que $20 \%$ do orçamento do Fundo de Amparo aos Trabalhadores (FAT) fossem direcionados a profissionais negros. Em maio de 2002, o então Presidente Fernando Henrique Cardoso assinou o Programa Nacional de Ações Afirmativas, propondo a adoção de mecanismos para promover a melhoria de "populações em desvantagem", mas não implementou cotas ou metas específicas (HTUN, 2004; TELLES, 2004, p. 72). Supostamente, todas essas medidas seriam implementadas utilizando a cor ou raça autodeclarada. Por fim, em 21 de março de 2003 criou-se a Secretaria Especial de Políticas de Promoção da Igualdade Racial (Seppir) para reafirmar o compromisso "com a construção de uma política de governo voltada aos interesses reais da população negra e de outros segmentos étnicos discriminados" (BRASIL. SEPPIR, 2010).

Na última década o debate acadêmico ao redor da raça também se tornou mais organizado. Dois exemplos recentes são a criação do grupo de estudos Observa, cujo objetivo é "coletar, produzir, sistematizar e disseminar dados sobre políticas de ação afirmativa no campo educacional superior no Brasil" (OBSERVA, 2010), e a criação do Laboratório de Análises Econômicas, Sociais e Estatísticas das Relações Raciais (Laeser) em 2006, cuja missão é "realizar pesquisas e atividades

não é explícita e supostamente foi deixada a critério da auto-identificação. de extensão universitária voltadas ao tema das relações raciais" (LAESER, 2010). Ambos os sítios possuem uma número considerável de artigos científicos e estatísticas que utilizam o recorte racial em suas análises. Juntamente com a criação de políticas raciais, essas duas iniciativas acadêmicas demonstram que se utiliza e fala-se mais em raça. Com isso, maior tem sido também a propensão a levar-se em conta, a "controlar-se o efeito" da cor da pele em estudos quantitativos.

A terceira razão contribuindo para que a cor da pele seja cada vez mais considerada em estudos quantitativos está relacionada com a crescente implementação de métodos estatísticos de análise. Por um lado, modelos de correlação e regressão facilitam os graus de sofisticação e de rigor analítico ao permitirem o isolamento de determinados efeitos de interesse. Mas, por outro lado, também facilitam a utilização e o controle da variável "cor" sem que considerações substantivas quanto ao real significado da variável "raça" sejam feitas.

Modelos de regressão são particularmente valiosos por permitirem a elaboração de cenários contrafactuais que ajudam a responder "o que aconteceria se" as características individuais e contextuais fossem outras, supondo que tudo o mais permaneça constante. Simulações desse tipo são a melhor maneira de aproximar modelos de associação a modelos de inferência causal. Quando unidades idênticas de estudo são expostas às mesmas condições e posteriormente avaliadas de maneira similar, quaisquer diferenças advindas da intervenção cujo efeito deseja-se avaliar podem ser medidas de maneira válida e sem a influência de fatores de confusão.

No caso da cor da pele, por exemplo, seria necessário que indivíduos classificados em categorias raciais distintas fossem idênticos em todas as suas outras características no início do experimento para que inferências causais relativas à cor pudessem ser feitas. Caso contrário, isto é, na ausência de condições iniciais de igualdade, pouco poderia ser dito ou inferido sobre o que analistas empíricos gostam de chamar de "efeito raça". Como a raça de uma pessoa não pode ser experimentalmente alterada, ela também não pode ser considerada uma causa, com um efeito bem definido e distinguível de fatores socioeconômicos e experiências contextuais vividas. Para que esse tipo de inferência fosse feita seria preciso que as 
unidades amostrais de análise fossem idênticas em tudo, exceto na sua cor ${ }^{4}$. Quando essas condições de igualdade não são satisfeitas, regressões e modelos estatísticos só são capazes de indicar diferenças a serem explicadas, não causas. O papel causal da raça está na sua habilidade em revelar diferenças socioeconômicas em diversos segmentos da população e não em explicá-las (HOLLAND, 2008).

As estimativas de discriminação salarial devido à raça, por exemplo, são comumente inferidas por meio de modelos de regressão padronizados (ex. Oaxaca-Blinder) capazes de isolar os fatores relacionados à produtividade (escolaridade, experiência) para determinar o salário dos empregados. Essa técnica fornece estimativas nãoenviesadas da disparidade média salarial em diversas categorias, incluindo o coeficiente residual atribuído à raça. Esses modelos, entretanto, não captam nenhum dos indicadores que seriam essenciais para concluir-se que há discriminação no mercado de trabalho, tais como o tratamento racial dado aos empregados por seus empregadores, a percepção das relações de trabalho e as respostas de ajuste e adaptação dos atores envolvidos (STEWART, 2008, p. 120). Para isso, estudos qualitativos seriam mais indicados.

A perversidade da abordagem estatística formal é relegar a raça a uma simplicidade dicotômica isenta de complexidades e significados. Brancos de um lado, pretos e pardos de outro, indígenas e amarelos ignorados. Quando simplesmente utilizada como variável independente, a cor da pele transforma-se em coisa, em uma fonte de heterogeneidade a ser controlada para evitar a contaminação da associação entre a variável resposta e covariáveis mais relevantes. No segundo semestre de 2001, por exemplo, $67 \%$ das publicações da American Sociological Review, do American Journal of Sociology, da Social Forces e de Demography incluíram a raça em modelos de

\footnotetext{
4 Devah Pager, da Universidade de Princeton, tem publicado vários estudos que tentam isolar por meio de projetos experimentais o efeito da raça (cf. PAGER, 2003; PAGER, WESTERN \& BONIKOWSKI, 2009). No Brasil, Antônio Sérgio Guimarães e Nadya Araújo Guimarães tentaram conduzir estudos experimentais, mas não tiveram sucesso devido ao custo e às dificuldades metodológicas impostas pelo contexto brasileiro (cf. GUIMARÃES \& GUIMARÃES, 2000).
}

regressão sem fazer qualquer menção quanto ao seu significado ou a sua implicação (JAMES, 2008, p. 43).

Além de contribuir para conceituar a raça como uma característica fixa, a adoção de modelos de regressão ou, mais especificamente, a adoção da variável indicadora da raça em modelos de regressão tem gerado uma inércia metodológica generalizada. Como a informação sobre cor da pele é cada vez mais prevalente em pesquisas sociais, o custo de se "controlar-se" por meio da raça em modelos de regressão é baixo, bastando para isso que se adicione uma dummy sinalizadora na especificação do modelo, sem se considerar as especificidades raciais separadamente ou por meio de termos interativos. Como decorrência, tem-se legitimado o processo em que a raça tende a ser considerada sem ser estudada ou questionada, o que contribui para aumentar a propensão para levála em conta de maneira "ampla, porém rasa" (MARTIN \& YEUNG, 2003).

O efeito raça, casualmente deduzido de tabelas descritivas, de contingência e de modelos de regressão, induz no imaginário do leitor uma relação causal vinculada a comportamentos específicos de determinados grupos raciais ou equivalentes a alguma escala nominal (por exemplo, o efeito de ser branco equivale a dois anos de estudo) que, além de transferir a atenção para sugestões causais, também reforça estereótipos ao assumir que as categorias raciais são homogêneas. $\mathrm{O}$ efeito raça desvia a atenção de situações complexas e simplifica-as em uma variável capaz de hierarquizar as chances ou as possibilidades de eventos do ciclo de vida, sem dar importância à construção ou ao estabelecimento de relações raciais que levam alguém a incluir-se em determinada categoria racial. O efeito raça, portanto, desvaloriza a formação racial ao simplificar um processo que é complexo e multifacetado, estabelecendo assim uma Sociologia da Raça vasta e superficial, "ampla e rasa".

É preciso lembrar que métodos quantitativos nem sempre são ferramentas objetivas, pois o emprego incorreto de estatísticas raciais pode legitimar o uso de metodologias que perpetuam a banalização da raça como categoria de controle e não como categoria de análise substantiva. Dados e modelos de regressão podem sinalizar o que está acontecendo em determinadas categorias raciais, 
mas dizem pouco sobre porque está acontecendo (ZUBERI, 2008, p. 6).

\section{LIMITAÇÕES E POSSIBILIDADES DE USO DA VARIÁVEL "RAÇA"}

Como medida quantificável, as limitações da raça estão vinculadas aos seus uso, interpretação e propósito analítico. A raça, como inserida em modelos de descrição e inferência, não está isenta de variações temporais, espaciais e contextuais. É preciso ficar claro que ela não é uma característica fixa e imutável e muito menos determinística. A raça não possui efeitos causais. Ninguém possui renda média elevada, chances maiores de casar-se, ter acesso a serviços de saúde ou entrar na faculdade porque é (auto)classificado como "branco". Ninguém possui habilidades inatas para jogar futebol, ser um bom cantor, desenvolver certa morbidade ou ser discriminado no emprego por ser "preto", "pardo", "branco", "amarelo" ou "indígena". O que realmente importa é como a sociedade responde à identificação racial individual. A questão pertinente está mais ligada às respostas da sociedade propriamente dita do que à aparência inata dos indivíduos. A identidade racial, e as respostas dadas a ela pela sociedade, são uma função do status social compartilhado e não das características individuais. A raça não é necessariamente o reflexo da cor da pele de um indivíduo, mas sim o reflexo da relação entre indivíduos e outras pessoas da sociedade (ZUBERI, 2008, p. 7).

A limitação da raça está na falta de entendimento do seu real significado por parte do analista e daqueles que a utilizam de maneira inapropriada. Como um indicador de heterogeneidades socioeconômicas, a variável "raça" serve ao seu propósito de monitoramento, acompanhamento e indicador de diferenças desde que o seu dinamismo seja (re)conhecido. A aplicação do conceito de raça é hoje uma necessidade teórica e prática nos estudos e processos sobre identidade étnica, conquista de direitos e justiça social de grupos fenotipicamente distintos. Nesse sentido, a erradicação do racismo e a luta contra a raça como um critério de segregação social e de exclusão de oportunidades requer que o termo - ou conceitos correlatos, como "cor" e "fenótipo" - seja mantido nas coletas de dados e nos registros e notificações das instituições, públicas ou particulares, ao menos enquanto perdurar a situação de flagrante desigualdade. É crucial, entretanto, que ao utilizar- se a cor da pele como um "controle de confusão" em análises de regressão, ou como um indicador de diferenças demográficas e socioecômicas, esteja-se atento para a natureza volátil da raça ao longo do tempo e do espaço. É necessário também que se reconheça o impacto que diferentes instrumentos ou formas de coleta podem ter sobre a informação racial, já que isso pode afetar de maneira relevante o retrato empírico da composição populacional pela raça e a percepção de variáveis distribuídas segundo a cor da pele (por exemplo: renda, fecundidade, esperança de vida, mobilidade social, acesso a universidade e participação política) (BAILEY, LOVEMAN \& MUNIZ, 2009).

Reconhecer as limitações do uso da variável "raça" em estudos quantitativos e em políticas públicas, entretanto, representa apenas o primeiro passo para começar-se a entendê-las. Para evitar que a variável "raça" continue a ser utilizada de maneira banal, ainda que com ressalvas quanto ao seu dinamismo e à sua natureza socialmente construída, o mais progressista seria que começássemos a estudar e a mensurar os fatores individuais e contextuais que contribuem para o estabelecimento e a mudança das fronteiras raciais, assim como o impacto que isso pode vir a ter sobre o nosso entendimento das desigualdades. Para ilustrar e esclarecer o argumento, é conveniente que se examine o foco e a abordagem de alguns estudos recentes publicados nos Estados Unidos. Esses estudos podem ser divididos em quatro categorias: 1) os que se preocupam em medir o grau de consistência entre diferentes medidas de raça e o impacto que isso pode ter em medidas de desigualdade (TELLES \& LIM, 1998; SAPERSTEIN, 2006; SAPERSTEIN \& SYKES, 2008); 2) os que incorporam e constroem medidas multidimensionais de raça para considerá-la uma medida complexa e multifacetada (SAPERSTEIN, 2008; BURTON, NANDI \& PLATT, 2010); 3) os que se preocupam em entender como e porque algumas pessoas classificam-se ou são classificadas de diferentes maneiras ao longo do tempo (PENNER \& SAPERSTEIN, 2008); 4) os que adotam uma metodologia analítica capaz de incorporar o contexto social e a dimensão temporal em estudos sobre discriminação e desigualdade (HORTON \& SYKES, 2008).

Ao estudar o impacto que a raça autodeclarada e aquela coletada pelo entrevistador podem ter sobre a desigualdade de renda nos Estados Unidos, 
Saperstein (2006) mostra que a inconsistência classificatória pode levar a diferentes conclusões sobre o grau de desigualdade. Em parte, isso ocorreria porque alguns não-brancos mais escolarizados e com maior poder aquisitivo estariam autoclassificando-se como brancos. É interessante notar que, mesmo a consistência da informação entre raça autodeclarada e observada sendo superior a $96 \%$, ainda há espaço para divergências de resultados quando se analisa o grau de desigualdade nos dois métodos de classificação. No caso brasileiro, um estudo utilizando dados do Rio Grande do Sul mostrou que as desigualdades étnico-raciais foram "discretamente maiores quando [a] cor/raça foi aferida por observador externo" (BASTOS et alii, 2008, p. 332). Resultados similares foram obtidos por Telles e Lim (1998) ao utilizarem dados representativos do Brasil urbano.

$\mathrm{Na}$ segunda linha de estudos está a tese de doutorado em Sociologia escrita por Saperstein (2008). A autora argumenta que uma abordagem multidimensional para a mensuração da raça pode revelar padrões de desigualdade mais claros do que quando apenas uma medida é empregada. Usando uma técnica estatística conhecida como análise de classes latentes (latent class analysis), ela demonstra que a raça não é simplesmente o que pensamos que somos, mas também como somos percebidos pelos outros. Ao combinar essas duas dimensões, ela sugere que se ganha uma visão mais completa do retrato racial norte-americano e de como ele tem-se alterado ao longo do tempo.

No terceiro grupo está um estudo comprovando que a raça é de fato uma construção social fluida. Utilizando dados da National Longitudinal Survey of Youth (NLSY) coletados ao longo de 20 anos, Penner e Saperstein (2008) mostram que pessoas desempregadas, encarceradas ou em situação de pobreza são mais propensas a identificarem-se e a serem identificadas como negras do que brancas, independentemente da classificação racial coletada no passado.

Por fim, na quarta categoria, Horton e Sykes (2008) sugerem uma forma original de modelarse o conceito de "racismo" levando-se em conta os níveis "micro" e "macro" a partir da abordagem hierárquica. A principal vantagem da operacionalização proposta está em permitir a inclusão de variáveis individuais e contextuais que variam no tempo. Dessa maneira, os autores são capazes de considerar influências contextuais sobre a desigualdade entre brancos e não-brancos. Surpreendentemente, após considerarem variáveis macrocontextuais no modelo, a associação entre raça e as variáveis dependentes (renda e valores imobiliários) passa de negativa para positiva. A contribuição mais relevante da abordagem multinível proposta pelos autores, entretanto, está na demonstração de como operacionalizar o paradigma construtivista da raça, segundo o qual as fronteiras raciais (racial boundaries) são afetadas pelo contexto social, podendo variar entre sociedades e ao longo do tempo.

Permeando esses estudos está a necessidade de conhecer-se o impacto que a reclassificação e a forma de coleta racial podem vir a ter sobre as conclusões derivadas de recortes raciais tidos como fixos e constantes. No Brasil, apesar da grande atenção dada ao debate sobre cotas raciais, esses estudos ainda são incipientes ou latentes. Ainda não conhecemos, por exemplo, quais seriam as consequências empíricas de adotar-se uma, duas, três ou várias medidas de coleta racial para definir-se quem é branco e quem é negro na alocação de benefícios, no retrato da desigualdade de renda e na distribuição e na dinâmica populacionais. Também não sabemos o que de fato estamos comparando quando dizemos que a expectativa de vida ao nascer dos negros em 2000 é maior do que aquela observada dez anos antes, já que essas comparações são claramente influenciadas pelo processo de reclassificação racial e pelos efeitos de composição. Por fim, especulamos que haja discriminação no mercado de trabalho já que negros ganham menos do que brancos, mesmo após a padronização das características produtivas desses dois grupos, mas ainda não conhecemos ao certo o processo por meio do qual a discriminação ocorre. Sabemos que ela existe quando o coeficiente residual dicotômico da variável "raça" mostra-se estatisticamente significativo, mas ainda não sabemos ao certo porque isso ocorre. Os níveis de discriminação têm diminuído para as coortes mais recentes (REIS \& CRESPO, 2005), mas não se sabe ao certo o quanto dessa diminuição é real e o quanto deve-se ao efeito de composição advindo da reclassificação racial. É preciso que os métodos, as pesquisas e as perguntas feitas sobre a raça evoluam para mostrar o que estamos deixando de aprender por ignorar o efeito das mudanças 
metodológicas e temporais no processo de (re)classificação racial. É uma agenda de pesquisa baseada no que não sabemos que ajudará a mudar o foco dado à raça de banal para cabal.

Para começar a pensar-se a raça como multifacetada é preciso que se combinem metodologias distintas de coleta e a partir delas construam-se intervalos de confiança estatística para que a incerteza de tais medidas seja incorporada. Essa prática elucidaria o tamanho da variabilidade presente no emprego de diferentes metodologias de mensuração racial e, ao mesmo tempo, incorporaria a incerteza inerente às amostras populacionais na apresentação de resultados. Além disso, a validade de medidas raciais também seria revigorada por meio de análises de concordância e consistência. Nesse sentido, análises similares àquelas conduzidas por Saperstein (2006) seriam bem-vindas para constatar-se o quanto a metodologia de coleta pode vir a influenciar a distribuição da variável de interesse. Procedimentos desse tipo aumentariam tanto a validade quanto a confiabilidade das informações sobre raça coletadas em pesquisas transversais.

Outro avanço para os que estudam raças seria avaliar o papel da reclassificação racial nas estatísticas apresentadas ao longo do tempo. Ainda não existem estudos no Brasil avaliando o quanto o acompanhamento de estatísticas fundamentadas em cortes raciais é influenciado pela reclassificação. Sabe-se que entre 1950 e 1980 $38 \%$ da população preta reclassificou-se como parda (CARVALHO, WOOD \& ANDRADE, 2004), mas não se sabe o impacto que isso pode ter tido na maneira como os indicadores de desigualdade, expectativa de vida ou qualquer outro resultado socioeconômico são percebidos no tempo. O nível médio de renda dos brancos, por exemplo, pode ter aumentado entre 1950 e 1980, mas sem dados longitudinais não se pode precisar o quanto dessa suposta variação de renda é legítima e o quanto deve-se à reclassificação de pardos para brancos e de pretos para pardos. Em outras palavras, o aumento da renda dos brancos pode ter sido uma decorrência da reclassificação dos brancos mais pobres para a categoria dos pardos, ou dos pardos mais ricos para o grupo dos brancos.

Sem que dados longitudinais sejam coletados e analisados, a mensuração do impacto da reclassificação racial sobre indicadores sociais temporais associados à raça permanecerá por tempo indeterminado na agenda de pesquisa futura. Sem se conhecer a opção racial individual feita no passado não se pode conhecer como essa opção pode ter-se ou não alterado no presente. Sem se conhecer esses fluxos temporais de (re)classificação, o máximo que se pode inferir sobre o processo de mudança racial são os saldos líquidos de reclassificação racial a partir da comparação entre populações projetadas e observadas, como feito por Carvalho, Wood e Andrade (2004), no caso do Brasil, e por Loveman e Muniz (2007), no caso de Porto Rico.

\section{SOBRE O USO DA RAÇA EM POLÍTICAS PÚBLICAS}

Sendo variável, a cor da pele não pode e nem deve ser entendida como imutável no tempo, mas sim em maio a condições sociais que permeiam percepções subjetivas, individuais e de terceiros. Comparar a variável "raça" ao longo do tempo ou quaisquer resultados de interesse associados a ela significa também comparar mudanças no significado social da variável raça ou "cor". O ideal seria que a variável raça fosse contextualizada e entendida em contextos históricos e sociais próprios. Quando nos esquecemos de que a variável raça não é apenas o resultado da autodesignação, mas também o resultado de escolhas internalizadas auto-impostas por um contexto externo, a confecção de estudos sociológicos passa a reforçar e a ser parte de um sistema de estratificação social. Perceber a variável "raça" como uma característica fixa e não como uma marca flexível de status social, é particularmente problemático para a implementação de políticas públicas que utilizam a cor da pele como um demarcador de benefícios e vantagens compensadoras de desigualdades sociais - e por três razões.

Em primeiro lugar, políticas públicas imediatistas nem sempre levam em conta a especificidade contextual ao definirem suas regras de implementação. Qual seria, por exemplo, a fundamentação empírica para que $20 \%, 30 \%, 40 \%$ ou $50 \%$ de determinado orçamento ou número de vagas sejam destinadas a negros? Que tipo de estudo de demanda, se é que existe algum, é realizado previamente para definir essas constantes de proporcionalidade e alocar tais benefícios? A definição desses percentuais não deveria 
considerar a especificidade do contexto no qual o benefício é proposto? Será que o percentual de cotas sugerido leva em conta o tamanho da disparidade que se quer reduzir? Mesmo que esses percentuais fossem fundamentados em análises rigorosas, é preciso ater-se ao fato de que números destinados a esse propósito são derivados de amostras populacionais: amostras são específicas para regiões e contextos sociais particulares, o que dificulta consideravelmente o estabelecimento de políticas federais universais. Seria ineficaz e perverso alocar, por exemplo, 20\% das vagas universitárias para negros em uma região onde apenas $5 \%$ da população autodeclarada negra tenha terminado o Ensino Médio e onde a proporção de pobres, independentemente da cor, seja similar. É preciso que o espaço de implementação de políticas raciais seja considerado de maneira rigorosa e sistemática para evitar que propostas de mitigação de desigualdades raciais sejam elaboradas e sugeridas de modo descontextualizado e implementadas de maneira sub-ótima.

A segunda razão que torna a raça um sinalizador impróprio para políticas públicas está vinculada ao seu dinamismo temporal. Por ser um atributo socialmente construído, influenciável pelos contextos, pelas experiências passadas, pelas interações sociais vividas, pelas percepções e pelo status, os números associados à raça utilizados para descrever a composição populacional, acompanhar tendências e mensurar a eficácia de políticas não são estritamente confiáveis. Por alterar-se ao longo do tempo e ser de difícil mensuração, a cor da pele, sozinha, não é uma fonte segura de informação e muito menos um critério objetivo para a concessão de benefícios.

Carvalho, Wood e Andrade (2004, p. 331), por exemplo, apresentam evidência de que grande parte dos autodeclarados pretos em 1950 reclassificaram-se como pardos em 1980. Em particular, após estimarem o quanto a população deveria crescer em cada categoria racial apenas por fatores demográficos e, ao compararem suas projeções com a população de fato observada, eles estimaram um déficit populacional de 38\% na categoria dos pretos e um ganho de $34 \%$ na categoria dos pardos, o que segundo eles seria um forte indício de reclassificação.

No Brasil, a instabilidade racial é agravada pela presença dos pardos, que podem pertencer tanto ao grupo dos brancos quanto ao grupo dos pretos. Quando forçados a escolher apenas entre as categorias branca ou preta, a população parda tende a dividir-se igualmente entre as duas opções de autoclassificação (BAILEY, 2009). Recortes raciais dicotômicos impostos, como agrupar pretos e pardos na mesma categoria, podem comprometer o entendimento e a descrição de determinada variável caso os "pardos" tenham características diferenciadas daquelas do grupo ao qual foram forçados a fazer parte. Lançando mão do corte de linha de pobreza, por exemplo, “dos quase 57 milhões de brasileiros pobres, são brancos $34,2 \%$, são pardos $58,7 \%$ e são pretos $7,1 \%$. O truque de somar pardos com pretos, denominando-os negros, faz $65,8 \%$ dos pobres. Se criássemos a categoria branquelos, como resultado da soma de brancos mais pardos, teríamos 92,9\% de branquelos pobres" (LESSA, 2007, p. 124)

Ao funcionar como uma válvula de escape para os incertos, a categoria dos pardos contribui para aumentar a instabilidade temporal classificatória. A mistura racial, representada pelos pardos, contribui para a ausência de distinções raciais claras e impossibilita assim a implementação de intervenções direcionadas a grupos raciais específicos (TELLES, 2004; BAILEY, 2008; TELLES \& SUE, 2009).

A terceira razão para não se utilizar a cor da pele como um sinalizador único de (des)vantagens na elaboração de políticas compensadoras está associada à sua incapacidade de apontar o âmago das desigualdades. A cor da pele é um demarcador imperfeito de desigualdades. Sendo a raça apenas uma aproximação para a demarcação de diferenças de renda, mobilidade social, estado de saúde e acesso a serviços, não se pode afirmar que ao se observar-se a raça, seja autodeclarada, seja imputada por terceiros, está-se de fato observando desigualdades reais nestas dimensões. Ser classificado em uma ou outra categoria racial pode ter algum impacto específico, mas na medida em que o nosso entendimento do que essas categorias significam muda, também mudam as conclusões das nossas análises estatísticas.

Os dados do IBGE e de outras pesquisas mostram que, em média, pardos e pretos encontram-se em desvantagem socioeconômica quando comparados aos brancos, mas isso não significa que todos os pardos e pretos encontram- 
se em desvantagem e nem indica que, entre todos os fatores geradores de desigualdade, os raciais sejam os mais importantes. Vários estudos mostram que o principal componente da desigualdade de renda está mais associado à escolaridade, à posição na ocupação e ao setor de atividade do que à raça (cf. BARROS \& MENDONÇA, 1995; RAMOS \& VIEIRA, 2000; BARROS, HENRIQUE \& MENDONÇA, 2002). Além disso, também há evidência demonstrando que as desigualdades de renda entre brancos, pardos e pretos são muito pequenas nos primeiros decis de renda, o que sugere que a maior parte da diferença média de renda entre grupos raciais devese ao hiato presente na parte superior da distribuição (ARIAS, YAMADA \& TEJERINA, 2004).

Seria injusto e ineficiente usar somente a cor da pele para decidir quem deve ter prioridade de acesso a determinado benefício ou serviço. Somente com a cor da pele corre-se o risco de catalisar-se, ao invés de mitigar-se, a desigualdade que de fato deseja-se alterar. Para a implementação de políticas seria melhor que se utilizasse a própria dimensão cuja desigualdade se quer diminuir, levando-se em conta suas especificidades contextuais e temporais, ao invés de empregar-se a raça como um sinalizador universal de diferenças. Nesse sentido, as cotas sociais, atualmente adotadas por várias universidades do país, são uma opção mais sábia do que o critério monotônico e dicromático inicialmente vislumbrado.

\section{COMENTÁRIOS FINAIS}

A crescente inclusão da raça em estudos quantitativos tem tido um resultado paradoxal na valorização e significação que tal variável vem adquirindo como categoria e objeto de análise. Por um lado, a incorporação da raça em estudos empíricos tem contribuído para aumentar a sua importância nos debates acadêmico, público e político. Por outro lado, a utilização sem ponderação e automatizada da variável em análises estatísticas tem contribuído para a sua superficialização e reificação. Assim, ao mesmo tempo em que a raça torna-se presente no debate político, ela também se torna invisível quanto ao seu real e complexo significado. A antinomia com a qual estudiosos e usuários da variável "raça" deparam-se é semelhante a empregar categorias raciais em suas análises de maneira simples e direta, mas sem negar os aspectos cruciais das experiências vividas e as complexidades contextuais que tornam a raça uma construção social (MARTIN \& YEUNG, 2003, p. 539).

A primeira solução para esse dilema seria continuar a utilizar a variável "raça", mas com as usuais ressalvas: 1) Dados étnico-raciais precisam ser tratados com cuidado devido às circunstâncias variáveis sob as quais são coletados; 2) o uso de descrições raciais podem refletir costumes, normas e tradições sociais em vez de origens genéticas ou hereditárias. Essas ressalvas são a saída mais conveniente para contornar-se a antinomia da raça.

A segunda saída seria abandonar a raça como uma "categoria de análise" e passar a tratá-la como uma "categoria de prática", como sugerido por Loveman (1999a) e Zuberi (2008). Isso significaria a "desracialização" das estatísticas sociais e a adoção de um arcabouço teóricoanalítico voltado para os processos de constituição, manutenção e declínio das fronteiras raciais. Segundo Zuberi e Bonilla-Silva (2008), a vantagem dessa abordagem seria um melhor entendimento de como as desigualdades operam e são criadas entre grupos raciais: "[...] we suggest the need to deracialize the analysis of race matters by conducting research not on the infamous 'race effect', but on how racial stratification produces disparate outcomes among racialized groups" (idem, p. 329).

A estratégia sugerida por esses autores, entretanto, tem um caráter muito mais complementar do que substituto. Perguntar por que determinado fenômeno ocorre só faz sentido após a verificação de que o fenômeno existe. Entender o que está por trás dos processos de discriminação racial e das desigualdades de renda é um passo que precisa ser dado após sabermos que as desigualdades e a discriminação de fato estão presentes. Para isso, é preciso que as categorias raciais existam e continuem a ser utilizadas como "categorias de análise". O uso continuado de técnicas estatísticas simplifica a complexidade da raça, mas também permite que ela seja a fonte e o caminho para a identificação de desigualdades entre indivíduos. Nesse sentido,

\footnotetext{
5 “....] Sugerimos a necessidade de desracializar a análise de temas raciais ao conduzir as pesquisas não sobre o infame 'efeito de raça', mas sobre como a estratificação racial produz resultados disparatados entre os grupos racializados" (tradução do revisor).
} 
o razoamento estatístico permite que haja discriminação ao fornecer prova da sua existência e dos seus custos sociais (GANDY, 2008, p. 306).

Empregar a raça como "categoria de prática", ou como "categoria de análise", é apenas uma manifestação da divisão entre os que estudam raça e dinâmicas raciais e os que usam o conceito de raça de maneira rotineira em seus estudos. Essa divisão é um reflexo de como a raça é conceituada por aqueles que a estudam em suas pesquisas, em contraste com aqueles que a usam e que tendem a tratá-la como uma característica fixa (JAMES, 2008, p. 42). O embate entre estudiosos da raça e analistas raciais é mais uma questão de abordagem, prioridade e foco dado à variável de interesse do que uma questão de incompatibilidade teóricometodológica.

O outro ponto de tensão associado ao uso da raça em estudos quantitativos diz respeito à sua consistência e à sua validade. Mensurar a raça é uma tarefa difícil não só porque os conceitos de cor da pele, etnia, origem, ancestralidade, nacionalidade e identidade sobrepõem-se, mas também porque existem variações significantes de taxonomia. Algumas taxonomias enfatizam a ancestralidade (Estados Unidos), outras a etnicidade (Reino Unido e Canadá) e outras a cor da pele (Brasil) (TRAVASSOS \& WILLIAMS, 2004, p. 671). É preciso estarmos cientes de que a construção de indicadores sociais pela raça é uma função de como as categorias raciais são definidas. É preciso lembrar que o tamanho da desigualdade entre brancos e negros, por exemplo, é determinado por meio da forma pela qual instituições e organismos oficiais medem a raça. Além disso, vale lembrar que as percepções que levam alguém a escolher determinada cor variam no tempo e no espaço. Devido a essas fontes de variação, as estatísticas raciais estão profundamente inseridas em incertezas: incerteza temporal, incerteza amostral, incerteza espacial, incerteza contextual e incerteza taxonômica. É crucial portanto que a agenda de pesquisa valorize metodologias capazes de mensurar tais incertezas na apresentação e na avaliação dos resultados (por exemplo: simulações Monte Carlo, bootstrap, análises comparativas).

Entre todas as incertezas possíveis, a única ainda imensurável no Brasil é a temporal. Devido à ausência de dados longitudinais, ainda não conhecemos o viés que o processo de reclassificação racial provoca na mensuração de resultados de interesse ao longo do tempo. Já nas demais dimensões (espacial, taxonômica, amostral e contextual), a variabilidade e a incerteza de resultados são observáveis e mensuráveis, devendo ser incorporadas nas conclusões e decisões políticas.

A questão que realmente importa não é se a raça deve ou não ser utilizada na produção de estudos quantitativos e na implementação de políticas visando à redução das desigualdades, mas sim se a variável pode ser utilizada de maneira consistente e válida. Nesse ponto, parte da consistência é assegurada pela manutenção das categorias oficiais ao longo do tempo, mas ainda é necessário que haja estudos para avaliar-se a concordância metodológica e temporal do processo de classificação racial. Ainda precisamos aprender como e quanto a falta de concordância entre metodologias de coleta afetam o tamanho e a dinâmica da desigualdade que se quer reduzir. Antes que esses estudos sejam produzidos para informar os debates público, político e acadêmico, a raça continuará a ser vista como uma indicadora problemática de desigualdades, cujas reais consequências só se pode especular ${ }^{6}$.

\footnotetext{
6 Dez recomendações sobre como e quando utilizar a variável "raça", sobretudo em estudos de saúde, podem ser encontradas em Travassos e Williams (2004).
}

Jerônimo Oliveira Muniz (jeronimomuniz@gmail.com) é economista, Mestre em Demografia e Doutor em Sociologia pela University of Wisconsin, Madison (Estados Unidos); também é pesquisador do Núcleo de Estudos de População (NEPO) da Universidade Estadual de Campinas (Unicamp) e Professor da Universidade Federal de Minas Gerais (UFMG). 


\section{REFERÊNCIAS BIBLIOGRÁFICAS}

ARAÚJO, E. M.; COSTA, M.; HOGAN, V.; ARAÚJO, T.; DIAS, A. \& OLIVEIRA, L. 2009. A utilização da variável raça/cor em Saúde Pública: possibilidades e limites. Interface (Botucatu), v. 13, n. 31, p. 383-394, out.-dez. Disponível em: http:/www.scielo.br/pdf/icse/ v13n31/a12v1331.pdf. Acesso em: 8.maio. 2010 .

ARAUJO, T. C. N. 1987. A classificação de "cor" nas pesquisas do IBGE: notas para uma discussão. Cadernos de Pesquisa, Rio de Janeiro, n. 63, p. 14-16, nov. Disponível em: http:/ /www.fcc.org.br/pesquisa/publicacoes/cp/arquivos/785.pdf. Acesso em: Acesso em: 8.maio. 2010

ARIAS, O.; YAMADA, G. \& TEJERINA, L. 2004. Education, Family Background and Racial Earnings Inequality in Brazil. International Journal of Manpower, Bingley, v. 25, n. 3-4, p. 355-374.

BAILEY, S. 2008. Unmixing for Race Making in Brazil. American Journal of Sociology, Chicago, v. 114, n. 3, p. 577-614, Nov.

2009. Legacies of Race: Identities, Attitudes, and Politics in Brazil. Palo Alto: Stanford University.

BAILEY, S. \& TELLES, E. E. 2006. Multiracial versus Collective Black Categories: Examining Census Classification Debates in Brazil. Ethnicities, London, v. 6, n. 1, p. 74-101.

BAILEY, S.; LOVEMAN, M. \& MUNIZ, J. 2009. The Dilemmas of Measuring Race in Inequality Studies: The Case of Brazil. Artigo apresentado no XXXIII Encontro Anual da Associação Nacional de Pós-Graduação e Pesquisa em Ciências Sociais, realizado de 26 a 30 de outubro de 2009 em Caxambu (Minas Gerais). Digit. Disponível em: http:// sec.adtevento.com.br/anpocs/inscricao/resumos/0001/TBR1092-1.DOC. Acesso em: 8.maio.2010.

BARROS, R. P. \& MENDONÇA, R. S. P. 1995. Os determinantes da desigualdade no Brasil. Texto para discussão n. 377. Rio de Janeiro: Instituto de Pesquisas Econômicas Aplicadas. Disponível em: http://www.ipea.gov.br/pub/td/ td_377.pdf. Acesso em: 8.maio.2010.
BARROS, R. P.; HENRIQUES, R. \& MENDONÇA, R. 2002. Pelo fim das décadas perdidas: educação e desenvolvimento sustentado no Brasil. Texto para discussão n. 857. Rio de Janeiro: Instituto de Pesquisa Econômica Aplicada. Disponível em: http:/www.ipea.gov.br/ $\mathrm{pub} / \mathrm{td} / 2002 / \mathrm{td}$ 0857.pdf. Acesso em: 8.maio. 2010

BASTOS, J. L.; PERES, M. A.; PERES, K. G.; DUMITH, S. C. \& GIGANTE, D. P. 2008. Diferenças socioeconômicas entre autoclassificação e heteroclassificação de cor/ raça. Revista de Saúde Pública, São Paulo, v. 42, n. 2, p. 324-334, fev. Disponível em: http:/ /www.scielo.br/pdf/rsp/v42n2/6412.pdf. Acesso em: 8.maio.2010.

BUENO, N. S. \& FIALHO, F. M. 2009. Race, Resources and Political Participation in a Brazilian City. Latin American Research Review, Pittsburgh, v. 44, n. 2, p. 59-83.

BURTON, J.; NANDI, A. \& PLATT, L. 2010. Measuring Ethnicity: Challenges and Opportunities for Survey Research. Ethnic and Racial Studies, London. First published in Feb. 9th.

CARVALHO, J. A. M.; WOOD, C. \& ANDRADE, F. C. D. 2004. Estimating the Stability of Census-Based Racial/Ethnic Classifications: The Case of Brazil. Population Studies, London, v. 58, n. 3, p. 331-343, Nov.

FREYRE, G. 1933. Casa-grande \& senzala: formação da família brasileira sob o regime da economia patriarcal. Rio de Janeiro: Schimdt.

GANDY, O. H. 2008. Being a Statistician Means Never Having to Say You're Certain. In: TUKUFU, Z. \& BONILLA-SILVA, E. (eds.). White Logic, White Methods: Racism and Methodology. Lanham: Rowman \& Littlefield.

GUIMARÃES, A. S. A. \& GUIMARÃES, N. A. 2000. Tratamento desigual de brancos e negros na procura de empregos na Região $\mathrm{Me}$ tropolitana de São Paulo. Documento de trabalho n. 3. São Paulo: USP. Disponível em: http://www.fflch.usp.br/sociologia/asag/ Tratamento $\% 20$ desigual $\% 20$ de $\% 20$ brancos $\%$ $20 \mathrm{e} \% 20$ negros $\% 20$ na $\% 20$ procura $\% 20 \mathrm{de} \%$ 20 empregos $\% 20$ na $\% 20$ Regia o $\% 20$ 
Metropolitana\%20de\%20Sao\%20Paulo.pdf. Acesso em: 8.maio.2010.

HOLLAND, P. W. 2008. Causation and Race. In: TUKUFU, Z. \& BONILLA-SILVA, E. (eds.). White Logic, White Methods: Racism and Methodology. Lanham: Rowman \& Littlefield.

HORTON, H. \& SYKES, L. 2008. Critical Demography and the Measurement of Racism: A Reproduction of Wealth, Status, and Power. In: TUKUFU, Z. \& BONILLA-SILVA, E. (eds.). White Logic, White Methods: Racism and Methodology. Lanham: Rowman \& Littlefield.

HTUN, M. 2004. From "Racial Democracy" to Affirmative Action: Changing State Policy on Race in Brazil. Latin American Research Review, Pittsburgh, v. 39, n. 1, p. 60-89.

JAMES, A. 2008. Making Sense of Race and Racial Classification. In: TUKUFU, Z. \& BONILLA-SILVA, E. (eds.). White Logic, White Methods: Racism and Methodology. Lanham: Rowman \& Littlefield.

JONES, C. P.; LAVEIST, T. A. \& LILLIEBLANTON, M. 1991. Race in the Epidemiologic Literature: An Examination of the American Journal of Epidemiology, 19211990. American Journal of Epidemiology, Oxford, v. 134, n. 10, p. 1079-1084.

LAGUARDIA, J. 2004. O uso da variável "raça" na pesquisa em saúde. Physis, Rio de Janeiro, v. 14, n. 2, p. 197-234, jul.-dez. Disponível em: http://www.scielo.br/pdf/physis/v14n2/ v14n2a03.pdf. Acesso em: 8.maio.2010.

LESSA, C. 2007. O Brasil não é bicolor. In: FRY, P.; MAGGIE, I.; MAIO, M.; MONTEIRO, S. \& SANTOS, R. (orgs.). Divisões perigosas: políticas raciais no Brasil contemporâneo. Rio de Janeiro: Civilização Brasileira.

LOVEMAN, M. 1999a. Is "Race" Essential? American Sociological Review, Chicago, v. 64, n. 6, p. 891-898, Dec.

1999b. Making "Race" and Nation in the United States, South Africa, and Brazil: Taking Making Seriously. Theory and Society, Heidelberg, v. 28, n. 6, p. 903-927, Dec. Disponível em: http://www.springerlink.com/ content/u85hm678717175w4/fulltext.pdf. Acesso em: 8.maio.2010.
LOVEMAN, M. \& MUNIZ, J. 2007. How Puerto Rico Became White: Boundary Dynamics and Intercensus Racial Reclassification. American Sociological Review, Washington, D. C., v. 72, n. 6, p. 915-939, Dec.

MARTIN, J. L. \& YEUNG, K.-T. 2003. The Use of the Conceptual Category of Race in American Sociology, 1937-99. Sociological Forum, Heidelberg, v. 18, n. 4, p. 521-543, Dec.

NIEMONEN, J. 1997. The Race Relations "Problematic" in American Sociology: A Case Study and Critique. The American Sociologist, New York, v. 28, p. 1, p. 15-54, Mar.

PAGER, D. 2003. The Mark of a Criminal Record. American Journal of Sociology, Chicago, v. 108, n. 5, p. 937-975, Mar.

PAGER, D.; BONIKOWSKI, B. \& WESTERN, B. 2009. Discrimination in a Low-Wage Labor Market: a Field Experiment. American Sociological Review, Washington, D. C., v. 74, n. 5, p. 777-799, Oct.

PAIXÃO, M. \& CARVANO, L. M. (orgs.) 2008. Relatório anual das desigualdades raciais no Brasil; 2007-2008. Rio de Janeiro: Garamond. Disponível em: http://www.laeser.ie.ufrj.br/ pdf/RDR_2007-2008_pt.pdf. Acesso em: 8.maio. 2010 .

PENNER, A. M. \& SAPERSTEIN, A. 2008. How Social Status Shapes Race. Proceedings of the National Academy of Sciences, Washington, D. C., v. 105 , n. 50, p. 19628-19630. Disponível em: http://www.pnas.org/content/105/50/ 19628.full.pdf + html. Acesso em: 8.maio.2010.

RAMOS, L. \& VIEIRA, M. L. 2000. Determinantes da desigualdade de rendimentos no Brasil nos anos 90: discriminação, segmentação e heterogeneidade dos trabalhadores. In: HENRIQUES, R. \& BARROS, A. (orgs.). Desigualdade e pobreza no Brasil. Rio de Janeiro: Instituto de Pesquisa Econômica Aplicada. Disponível em: http:// www.ipea.gov.br/sites/000/2/1ivros/ desigualdadepobrezabrasil/capitulo06.pdf. Acesso em: 8.maio.2010.

REIS, M. C. \& CRESPO, A. R. V. 2005. Race Discrimination in Brazil: An Analysis of the Age, Period and Cohort Effects. Texto para discussão n. 1 114. Rio de Janeiro: Instituto 
de Pesquisa Econômica Aplicada. Disponível em: http://www.ipea.gov.br/pub/td/2005/ td 1114.pdf. Acesso em: 8.maio. 2010.

REITHER, E. N.; HAUSER, R. M. \& YANG, Y. 2009. Do Birth Cohorts Matter? Age-PeriodCohort Analyses of the Obesity Epidemic in the United States. Social Science \& Medicine, New York, v. 69, n. 10, p. 1439-1448, Nov.

RIBEIRO, C. A. C. 2009. Desigualdade de oportunidades no Brasil. Belo Horizonte: Argvmentvm.

SAPERSTEIN, A. 2006. Double-Checking the Race Box: Examining Inconsistency between Survey Measures and Observed and SelfReported Race. Social Forces, Chapel Hill, v. 85, n. 1, p. 57-74, Sept.

2008. (Re)Modeling Race: Incorporating Racial Theory into Survey Research on Inequality. Thesis ( $\mathrm{PhD}$ in Sociology and Demography). University of California.

SAPERSTEIN, A. \& SYKES, B. L. 2008. What You See and What She Gets: Isolating the Effect of Inconsistent Racial Classification on Women's Earnings and Income. Article presented at the Population Association of America Annual Meeting, occurred at New Orleans, in April 17th-19th. Disponível em: h t t p : / / p a a 2008 .princeton.ed u / download.aspx?submissionId=81630. Acesso em: 8.maio.2010.

SCHWARTZMAN，L. 2007. Does Money Whiten? Intergenerational Changes in Racial Classification in Brazil. American Sociological Review, Washington, D. C., v. 72, n. 6, p. 940963.

SIMÕES, S. \& JERONYMO, M. 2007. Quem é negro no Brasil? Identidade racial e sistemas de classificação em uma sociedade miscigenada. In: AGUIAR, N. (org.). Desigualdades sociais, redes de sociabilidade e participação política. Belo Horizonte: UFMG.

STEWART, Q. 2008. Swimming Upstream: Theory and Methodology in Race Research. In: TUKUFU, Z. \& BONILLA-SILVA, E. (eds.). White Logic, White Methods: Racism and Methodology. Lanham: Rowman \& Littlefield.

TELLES, E. E. 2004. Race in Another America: The Significance of Skin Color in Brazil. Princeton: Princeton University.

TELLES, E. E. \& LIM, N. 1998. Does It Matter Who Answers the Race Question? Racial Classification and Income Inequality in Brazil. Demography, Silver Spring, v. 35, n. 4, p. 465474, Nov.

TELLES, E. E. \& SUE, C. A. 2009. Race Mixture: Boundary Crossing in Comparative Perspective. Annual Review of Sociology, Palo Alto, n. 35, p. 129-146.

THEODORO, M. (org.) 2008. As políticas públicas e a desigualdade racial no Brasil: 120 anos após a abolição. Brasília: Instituto de Pesquisa Econômica Aplicada. Disponível em: http://www.ipea.gov.br/sites/000/2/livros/ Livro_desigualdadesraciais.pdf. Acesso em: 8.maio. 2010

TRAVASSOS, C. \& WILLIAMS, D. R. 2004. The Concept and Measurement of Race and Their Relationship to Public Health: A Review Focused on Brazil and the United States. $\mathrm{Ca}$ dernos de Saúde Pública, Rio de Janeiro, v. 20, n. 3, p. 660-678, maio-jun. Disponível em: http://www.scielo.br/pdf/csp/v20n3/03.pdf. Acesso em: 8.maio.2010.

WILLIAMS, D. R. 1994. The Concept of Race in Health Services Research: 1966 to 1990. Health Services Research, Chicago, v. 29, n. 3, p. 261-274, Aug.

ZUBERI, T. 2001. Thicker than Blood: How Racial Statistics Lie. Minneapolis: University of Minnesota.

2008. Deracializing Social Statistics: Problems in the Quantification of Race. In: TUKUFU, Z. \& BONILLA-SILVA, E. (eds.). White Logic, White Methods: Racism and Methodology. Lanham: Rowman \& Littlefield.

ZUBERI, T. \& BONILLA-SILVA, E. 2008. White Logic, White Methods: Race, Epistemology, and the Social Sciences. Lanham: Rowman and Littlefield. 


\section{OUTRAS FONTES}

BRASIL. SEPPIR. 2010. O que é. Brasília: Secretaria Especial de Políticas de Promoção da Igualdade Racial. Disponível em: http:// www.presidencia.gov.br/estrutura presidencia/seppir/sobre/. Acesso em: 4.maio.2010.

LAESER. 2010. Missão. Rio de Janeiro: Laboratório de Análises Econômicas, Sociais e Esta- tísticas das Relações Raciais. Disponível em: http://www.laeser.ie.ufrj.br/missao.asp. Acesso em: 4.maio.2010.

OBSERVA. 2010. Objetivos. Rio de Janeiro: Universidade Federal do Rio de Janeiro. Disponível em: http://www.observa.ifcs.ufrj.br/sobre/ index.htm. Acesso em: 4.maio.2010. 


\section{ON THE USE OF THE VARIABLE RACE-COLOR IN QUANTITATIVE STUDIES}

\section{Jerônimo Oliveira Muniz}

The increased inclusion of race in Brazilian public debate, the increase of its usage in opinion polls and monitoring and the ease with which it has been included in statistical models has created a paradox regarding its importance. While skin color has been gaining salience in public debate, it has also lost substantive importance as a complex and dynamic social construct through the superficial way in which it is being employed - as a permanent and immutable category - in quantitative studies. This bibliographic essay discusses the factors that have contributed to such a tendency, looking at national and international literature produced over the last 10 years. We question the use of race in public policies, inquiring into its trustworthiness, variability and validity, and consider the limitations and possibilities of using race as a marker of difference. The essay concludes by suggesting a research agenda meant to increase understanding and reduce the uncertainties associated with the usage of "race" as a variable in quantitative studies.

KEYWORDS: race; skin color; Brazil; validity; trustworthiness; confidence level; stability; taxonomy; public policies. 
SUR L'UTILISATION DE LA VARIANTE RACE-COULEUR DANS DES ÉTUDES QUANTITATIFS

Jerônimo Oliveira Muniz

La croissante inclusion de la race dans le débat politique brésilien, l'augmentation de sa disponibilité dans des recherches d'opinion et la facilité d'inclusion de cette variable dans des modèles statistiques, a provoqué dernièrement un paradoxe sur l'importance de la race. Au même temps que la couleur de peau gagne un avantage au débat politique, elle perd aussi son importance substantielle comme une formulation sociale complèxe et dynamique, car elle est utilisée de façon superficielle, comme une cathégorie permanente et immuable dans des études quantitatifs. Cet analyse bibliographique discute les facteurs qui contribuent pour cette tendance, en considérant la littérature nationale et internationale produite les derniers dix ans. On questionne l'utilisation de race dans des politiques publiques en faisant attention à leur fiabilité, variabilité et validité, et on discute les limitations et possibilités de l'utilisation de la race comme un délimitateur de différences. L'analyse se termine en suggérant un agenda de recherche pour améliorer la compréhension et reduire les incertitudes associées à l'utilisation de la variante « race», dans des études quantitatifs.

MOTS-CLES : race, couleur de peau, Brésil, validité, fiabilité, stabilité, taxonomie, politiques publiques. 